\title{
História
}

\section{Entrevista com Dermeval Saviani}

\author{
Interview with Dermeval Saviani
}

\section{Entrevista con Dermeval Saviani}

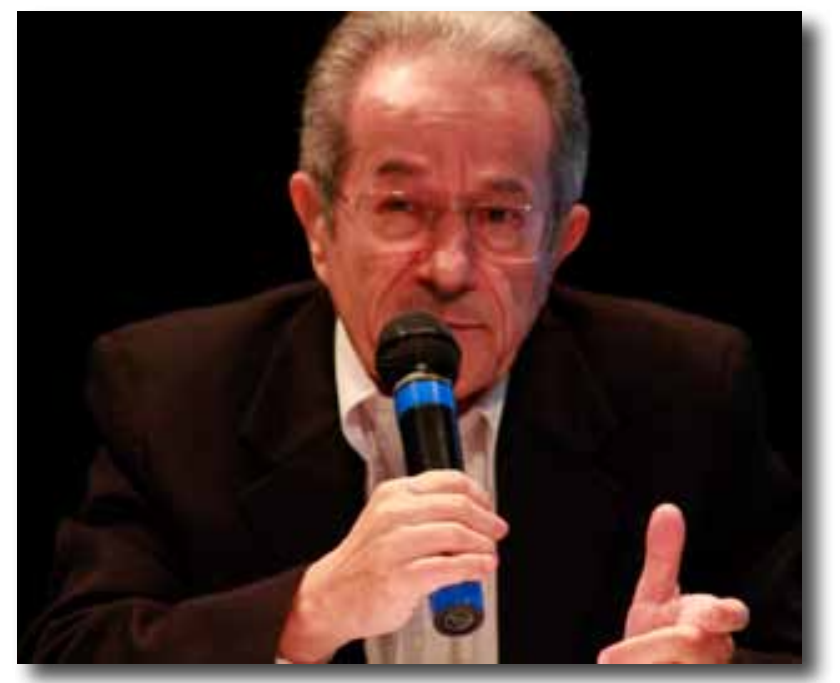

Fonte: http://pedagogiahistoricocritica.blogspot.com.br/p/palestrantes-e-conferencia-de.html

Graduado em Filosofia e doutor em Filosofia da Educação. Atualmente é Professor Titular aposentado da Universidade Estadual de Campinas, sendo Professor Emérito desta universidade, Pesquisador Emérito do CNPq e Coordenador Geral do Grupo de Estudos e Pesquisas História, Sociedade e Educação no Brasil (HISTEDBR).

ENTREVISTADORA: Neide da Silveira Duarte de Matos Organizadora e co-autora: Sonia Mari Shima Barroco

A presente entrevista foi concedida pelo Professor Dr. Dermeval Saviani (Unicamp) em agosto de 2015, na Universidade Estadual do Oeste do Paraná - Unioeste - campus Francisco Beltrão. A proposta para esta atividade surgiu na disciplina Ensino Superior: Políticas Públicas e Atuação Docente, do Programa de Pós-Graduação em Psicologia Mestrado e Doutorado (PPI/UEM). As indagações foram organizadas a partir de um trabalho em grupo'. Destacamos sua experiência no âmbito educacional, sendo reconhecidas suas pesquisas e atuação em Políticas Públicas e no Ensino Superior (Saviani, 1985; 1987, 1998, 1999) entre outras; consideramos ser uma personalidade reconhecida para tratar da temática da citada disciplina, além de tantas outras. Em mo-

1 Os pós-graduandos são Camila Turati Pessoa, Gustavo Lacatus, Juliana Biazze Feitosa, Leonardo José Freire Cabó, Mirian Alves Carvalho, Neide da Silveira Duarte de Matos. mentos de discussão do papel da educação formal, em diferentes níveis e modalidades, do papel das universidades em tempos de crescentes contradições sociais e da necessidade de reflexões sobre a formação e atuação de professores para o Ensino Superior e de pesquisadores, quando se avolumam conflitos que se materializam na "díade" governos (federal, estadual e municipal) $X$ categorias docentes, consideramos oportuna a divulgação da entrevista.

Neide: Professor Saviani, o senhor teve uma ampla participação nos debates para a proposição da Lei de Diretrizes e Bases da Educação Nacional LDBEN, 9394/-96. O senhor poderia apontar os aspectos fundamentais que esta lei trouxe ao Ensino Superior?

Prof. Saviani: Em primeiro lugar, acho que é bom esclarecer que eu tive uma participação na formulação do projeto de Lei original na Câmara de Deputados, mas depois 
este projeto foi sofrendo alterações e, embora tenha sido aprovado na Câmara preservando boa parte do espírito da proposta original, uma vez passado para o Senado Federal o governo interferiu, a partir da sua base no parlamento, no início da gestão FHC (Fernando Henrique Cardoso), em fevereiro/março de 1995, provocando uma reviravolta total nos rumos do projeto. Naquele momento, por meio de uma "manobra regimental", o projeto, que já havia sido aprovado na Câmara dos Deputados e também na Comissão de Educação do Senado na forma do Substitutivo Cid Sabóia e, consequentemente, já havia sido encaminhado ao plenário do Senado em 12 de dezembro de 1994 para aprovação final, foi obrigado a retornar à Comissão de Constituição e Justiça, onde foi designado relator Darci Ribeiro. O deputado Darci Ribeiro em articulação com o MEC (Ministério de Educação) apresentou outro substitutivo, e este é que se converteu na LDB, a Lei de Diretrizes e Bases, aprovada em dezembro de 1996. Mas a pergunta indaga o que essa lei trouxe em relação ao Ensino Superior. $\mathrm{Na}$ verdade ela não trouxe muita coisa relevante, porque no fundamental foi mantida no ensino superior aquela estrutura definida pela Lei 5.540 de $1968^{2}$. Então as mudanças substantivas foram introduzidas naquela legislação tais como o regime de créditos, a matrícula por disciplina, os cursos semestrais, a departamentalização. Todas essas mudanças foram introduzidas e elas permaneceram, pois não foram alteradas pela LDB 9394/96. Mas, o que a gente poderia destacar dessa LDB que trouxe de novo, em relação à situação anterior, são alguns poucos pontos.

A primeira inovação foi a introdução dos "cursos sequenciais por campo de saber, de diferentes níveis de abrangência, abertos a candidatos que atendam aos requisitos estabelecidos pelas instituições de ensino" (Art. 44, inciso I). Como se vê, a lei deixou em aberto sua definição e formas de organização. Passados quase 20 anos da aprovação da LDB, tal inovação parece ter tido pouco efeito prático.

A segunda inovação é a permissão de se organizar universidade por campo específico do saber (§ único do Art. 52) porque até aí a universidade, conforme diz o nome, cuidava do conjunto dos estudos voltados para o desenvolvimento das ciências, das letras, das artes, e a formação dos profissionais de nível superior que exigem fundamentação científica. Então uma universidade teria que abarcar várias áreas e por isso a legislação anterior colocava que para se construir uma universidade era preciso haver pelo menos três faculdades, que em geral eram aquelas tradicionais, que são medicina, engenharia e de direito, e a legislação de 1931, dos estatutos da universidade, colocou também a faculdade de educação, ciências e letras. Em suma, a concepção de universidade era a de que ela deveria abarca o mais amplamente possível os vários domínios do conhecimento humano. Essa LDB tornou possível que se organizasse universidade por uma área específica apenas; foi isto que fez com que a Faculdade Paulista de Medicina, que era a única

2 Brasil. (1968). Lei 5.540/1968. Fixa normas de organização e funcionamento do ensino superior e sua articulação com a escola média.(Regulamentada pelo Decreto 464/69, de 11/02/1969). escola federal existente na cidade de São Paulo, por encampação de uma faculdade particular, pelo governo federal, após a entrada em vigor da atual LDB tenha se transformado na Universidade Federal de São Paulo. Assim, mesmo limitada apenas à área da medicina, a Escola Paulista de Medicina virou universidade. Na verdade, porém, tendo virado universidade, ela também começou a ampliar suas áreas de atuação e hoje ela é uma universidade com características muito próximas das demais tendo, além da medicina, outros cursos também da área de ciências humanas. Enfim, essa é a primeira inovação desta LDB: ela permite que se organize uma universidade em uma determinada área do saber sem a necessidade de abarcar amplamente os conhecimentos.

Outra inovação que consta desta LDB é a elevação da formação de professores ao nível superior (Art. 62). Esse artigo determina que os professores de um modo geral, de todos os níveis de ensino, deverão ser formados em nível superior acrescentando-se, porém, na sequência da redação, "admitida como formação mínima para o exercício do magistério na educação infantil e nas quatro primeiras séries do ensino fundamental, a oferecida em nível médio, na modalidade Normal". Mas essa inovação da lei trouxe consigo dois problemas: um erro de português e uma falha de técnica legislativa. O erro de português apareceu nas Disposições Transitórias quando se afirma que "até o fim da Década da Educação somente serão admitidos professores habilitados em nível superior ou formados por treinamento em serviço" ( $\S 4^{\circ}$ do Art. 87). Ora, isso significa, então, que nos dez primeiros anos de vigência da lei somente seriam admitidos professores formados em nível superior. Depois disso, essa exigência não seria mais necessária, podendo-se admitir professores sem formação superior. Obviamente, a redação correta seria: a partir do final da década da educação somente serão admitidos professores formados em nível superior, indicando que os dez primeiros anos seriam um período de transição permitindo que aqueles que não tinham formação superior pudessem satisfazer essa exigência. Alertei na época, mas ninguém atentou para este problema porque o espírito daquele artigo era elevar a formação de professores ao nível superior. Então, embora esse enunciado tenha figurado no texto da lei, ninguém imaginou que isso autorizaria que depois da década da educação a formação não precisasse ser de nível superior. Na verdade, todo mundo entendeu o espírito, embora o texto da lei dissesse o contrário. Mas a outra falha, a de técnica legislativa, essa, sim, teve consequência e acabou por invalidar a inovação que se pretendia introduzir. Isso porque o corpo da lei corresponde às disposições permanentes. Exatamente por isso as leis apresentam, ao final, um título relativo às Disposições Transitórias para regular os procedimentos no período de transição entre as normas anteriores e aquelas instituídas pela nova legislação. Assim sendo, obviamente as disposições transitórias não podem prevalecer sobre as disposições permanentes. Ora, como a LDB colocou no corpo da lei que a formação deveria ser, em regra, no nível superior, mas admitiu como formação mínima a de nível médio na modalidade normal, então isso significa que, 
permanentemente, admitia-se a formação em nível médio. Assim, a técnica legislativa correta implicaria que no corpo da lei se fixasse apenas a regra: os professores, para atuar em qualquer nível de ensino, deverão ter formação de nível superior. Como a lei entraria em vigor na data de sua publicação, no caso, 23 de dezembro de 1996, obviamente não seria razoável, nessa data, demitir todos os professores que não tinham formação superior. Então era preciso fixar um período de transição para que essa regra entrasse em plena vigência. E nas Disposições Transitórias esse período foi fixado em 10 anos. Assim, fixada no corpo da lei a regra da formação em nível superior para todos os professores de qualquer nível de ensino, o artigo correspondente das Disposições Transitórias deveria ser assim redigido: Até o final da década da educação admitir-se-á, como exigência mínima, a formação em nível médio na modalidade normal. Consequentemente, nesse período de transição aqueles que não tinham, ainda, formação superior teriam de buscar obtê-la para poder continuar no magistério porque depois dos 10 anos quem não se formou em nível superior teria que ser removido do exercício do magistério. Esse seria o espírito da lei. Mas, por conta da falha de técnica legislativa, logo que a lei foi aprovada os mantenedores de escolas normais de nível médio levantaram a argumentação de que, estando no corpo da lei, era uma disposição permanente. No final o governo, em lugar de mandar ao Congresso um projeto corrigindo essa falha, encampou que o nível médio poderia ser mantido. E aquela inovação acabou ficando inoperante.

O quarto dispositivo que consta também na LDB sobre o ensino superior é a atribuição ao curso de pedagogia de formar os profissionais da educação para administração, planejamento, inspeção, supervisão e orientação educacional, admitindo-se sua formação também em nível de pós-graduação (Art. 64). Com isso a lei acabou mantendo algo que o movimento pela reformulação dos cursos de formação de educadores vinha considerando que não deveria ser mantido. Em lugar disso, o movimento que desembocou na criação da ANFOPE considerava, consoante o princípio da docência como base da formação do educador, que o curso de pedagogia deveria centrar-se na formação de professores para a educação infantil e o ensino fundamental e não para as habilitações técnicas que haviam sido instituídas pelo Parecer 252 de $1969^{3}$. E isso até gerou um problema quando da aprovação das diretrizes curriculares nacionais do curso de pedagogia. Essas diretrizes, que foram organizadas de certo modo com assessoria da ANFOPE (Associação Nacional pela Formação de Profissionais da Educação), foram aprovadas pelo Conselho Nacional de Educação com um dispositivo definindo que a formação dos especialistas seria feita na pós-graduação. Enviado esse documento ao MEC para homologação, na análise técnica dos aspectos jurídicos se observou que o referido dispositivo contrariava o disposto na LDB e, por isso, não podia ser mantido. Em

3 Brasil (1969). Parecern.252/69. Estudos pedagógicos superiores. Mínimos de conteúdo e duração para o curso de graduação em pedagogia. Relator: Valnir Chagas. Documenta, Brasília. (1-100), p.101-117. consequência, o MEC devolveu o processo ao Conselho Nacional de Educação propondo uma emenda naquele artigo da Resolução compatibilizando-a com o texto da Lei. Então, a possibilidade de se formar especialistas nessas quatro habilitações em nível de graduação no curso de pedagogia está mantida porque a lei assim dispôs.

Enfim, outra inovação dessa LDB foi a criação dos Institutos Superiores de Educação com a Escola Normal Superior, como o lócus próprio da formação de profissionais para a educação básica (Art. 63) que, entretanto, acabou não vingando na prática. Basicamente são esses os pontos de inovação que, entretanto, tiveram exíguo efeito prático.

Neide: Estamos discutindo na disciplina "Políticas Públicas e Docência no Ensino Superior" (PPI/UEM), alguns aspectos da formação de professores para atuar no ensino superior. Debatemos inclusive o que poderia ser entendido hoje, na atualidade, como sucesso e fracasso escolar nesse nível, bem como as contribuições da psicologia escolar para o ensino superior. Gostaríamos que o senhor pudesse apontar alguns elementos da pedagogia histórico-crítica para esse debate.

Prof. Saviani: Do ponto de vista da pedagogia histórico-crítica o ensino superior tem o papel de formar os profissionais em nível superior e também de desenvolver a cultura superior. Mas isso é alguma coisa que atualmente está sofrendo mutações bastante fortes, porque o ensino superior está perdendo essa característica e hoje há uma tendência a se elevar a ele um conjunto de atividades que a rigor não exigiria formação superior. Há uma série de atividades que são práticas, de caráter técnico, que não demandam uma fundamentação científica específica e, portanto, não exigiriam a formação em nível superior. Então, as profissões que exigem uma formação em nível superior são as de caráter tecnológico, entendida a tecnologia como a técnica fundada na ciência. Então, a técnica, que é a maneira considerada correta de se executar uma tarefa, pode ou não ter fundamentação científica. Por exemplo, o curso de cabeleireiro. Existe a maneira correta de se executar essa tarefa, que distingue então o técnico do curioso. Qualquer um pode cortar cabelos. Acontece, porém, que quando é um curioso que executa essa tarefa ele não domina as regras de como fazer essa tarefa e, enquanto tal, vai executá-la na base do acerto e erro. O resultado é que ele demora mais tempo e a tarefa é feita de forma menos perfeita. O técnico é aquele que domina as regras e as aplica. Com isso, ele faz a tarefa em menos tempo e de forma mais perfeita aplicando aquelas regras que ele aprendeu ao se formar nessa profissão, e que, como não exige fundamentação científica, pode ser objeto de cursos rápidos ou cursos técnicos, ou cursos específicos para isso. Quando se trata de atividades que exigem fundamentação científica, então a técnica que é utilizada é baseada na ciência, por isso ela se chama tecnologia, porque o sufixo logia significa ciência de, estudo de. Então, é uma técnica fundada na ciência. É nesse campo que nós temos as engenharias, que são atividades que exigem a fundamentação das ciências físico-matemáticas; a medicina, visto que as atividades médicas também são 
tecnologias, porque são profissões, atividades que exigem a fundamentação científica das ciências biológicas complementadas também pela química, pela física. Então, a formação de nível superior está voltada para as profissões que exigem a fundamentação científica. É por isso que as universidades estão sendo definidas como o lugar de desenvolvimento da filosofia, das ciências, das letras e das artes. Mas, ultimamente, as atividades que não exigiriam isso, como o turismo, a gastronomia, entre outras, estão sendo elevadas ao nível superior. Isso está provocando também uma alteração no próprio caráter das instituições. Vejam o caso do dito sistema "S" - SENAI, SENAC, SENAR e agora existe também o SENAT. Esses organismos foram criados na década de 1940, no Estado Novo, como Serviço Nacional de Aprendizagem Industrial, Serviço Nacional de Aprendizagem Comercial e, já mais ao final do Estado Novo, Serviço Nacional de Aprendizagem Agrícola. Constituíam-se em um serviço de aprendizagem para formar os trabalhadores da indústria, do comércio, da agricultura. Então, eram cursos que representavam a versão das corporações de ofícios manuais na sociedade capitalista. $\mathrm{Na}$ idade média existiam as corporações de ofício manuais para formar os trabalhadores manuais e a universidade era a corporação para formar os trabalhadores intelectuais. Na década de 1940 foram criados os cursos técnicos para formar o técnico de nível médio, industrial, agrícola e comercial, no mesmo nível do técnico normal, para formar os professores do ensino primário. Nos cursos de aprendizagem não se exigia formação prévia, porque era para formar o trabalhador que vai atuar nas empresas. Por isso o governo queria que fosse assumido pelos patrões, pelos empresários. Os patrões resistiram porque não estavam querendo assumir esse compromisso. Mas Getúlio ameaçou entregar para os sindicatos de trabalhadores. Diante dessa amaça os empresários aceitaram essa incumbência dando origem àquilo que conhecemos hoje como "Sistema S", cujo papel era organizar os cursos de aprendizagem para formar os trabalhadores manuais. No entanto, ultimamente essas entidades passaram a atuar em nível médio, em seguida operando, também, como faculdades e agora atuam também na pós-graduação. Então a formação em nível superior está passando por essas mutações. $\mathrm{Na}$ perspectiva da pedagogia histórico-crítica a especificidade da formação em nível superior consiste na preparação dos profissionais voltados para o trabalho intelectual, ou seja, que se destinam às profissões de caráter tecnológico. Mas esse é o aspecto do Ensino Superior. Além desse aspecto a Educação Superior deveria abarcar também programas de cultura superior sendo abertos à sociedade em geral, de modo que mesmo aqueles que não têm acesso ao ensino superior porque não exercem profissões que implicam uma formação de nível superior, deveriam ter acesso a eles. O objeto desses Programas de Cultura Superior seria a discussão dos grandes problemas que afetam a sociedade e a humanidade. Essa proposta eu já havia feito para a LDB e retomei agora num livro que lancei em 2014, Sistema Nacional de Educação e Plano Nacional de Educação: significado, controvérsias e perspectivas, no qual delineio a organiza- ção do sistema nacional de educação sob o ponto de vista dos conteúdos a serem ministrados na educação básica e na educação superior. Propus a distinção entre esses dois aspectos porque atualmente o acesso à Cultura Superior está condicionado pelo acesso ao Ensino Superior, que não necessita ser universalizado porque não são todos que vão atuar nas profissões de nível superior. Ora, na medida em que o acesso ao Ensino Superior coincide com o acesso à Cultura Superior ${ }^{4}$, esta acaba resultando num privilégio daqueles que exercem profissões tecnológicas ficando, os demais, alijados desse acesso.

A perspectiva da pedagogia histórico-crítica visa à superação dessa sociedade baseada na posse e usufruto dos produtos do trabalho por parte dos donos dos meios de produção que, comprando a força de trabalho ganham o direito de se apropriarem do que os trabalhadores são capazes de produzir. A superação dessa forma social envolve socializar os meios de produção, e, portanto, lutar para que os frutos do trabalho da sociedade estejam acessíveis a todos os seus membros, segundo aquilo que Marx observa na Crítica ao Programa de Gotha: "de que cada um segundo as suas capacidades e a cada um segundo as suas necessidades". Enfim, o Ensino Superior teria a função de assegurar formação aos profissionais destinados ao trabalho de caráter tecnológico; e a Cultura Superior não seria um privilégio dessa categoria social, mas estaria aberta a toda a população.

Neide: A pedagogia histórico-crítica se constitui aproximadamente na década de 1980, principalmente quando o senhor lança Escola e Democracia e aponta seus fundamentos e perspectivas. Desde a década de 90 vivemos o recuo da teoria, apontado pela professora Maria Célia Marcondes. Como o senhor analisa esse distanciamento em meio ao contexto do produtivismo presente no Ensino Superior e na Pós-graduação e que tem caracterizado o trabalho docente?

Prof. Saviani: Nós estamos vivendo aquilo que pode ser considerado a fase final do capitalismo, que tomou conta do mundo inteiro, não tendo mais para onde se expandir, passando crescentemente a criar problemas que não tem condições de resolver. Neste sentido, tem uma sobrevida na medida em que, do ponto de vista da produção, ele desenvolve uma produção destrutiva, ou seja, se se destrói é preciso reconstruir. Para reconstruir pode-se fazer a partir destas relações de produção. Por isso é que a produção hoje está ancorada na destruição. Há a promoção da destruição pelas guerras, guerras mais amplas, menos amplas, guerras localizadas; pela destruição do meio ambiente: cada desgraça ambiental implica investimentos para reconstruir; há a destruição pelos desastres de trânsito, que acontece constantemente e que requer também investimentos de reconstrução. E hoje a criminalidade, a violência, são formas de destruição que estão no interior dessa sociedade. Não são acontecimentos externos, esporádicos. Ao contrário, são

4 Por acesso à Cultura Superior o professor Saviani entende a forma de possibilitar que todos os membros da sociedade, independentemente do tipo de atividade profissional a que se dediquem, participem plenamente da vida cultural, em sua manifestação mais elaborada. 
estruturais a essa forma de sociedade. Nesse contexto, a classe dominante não tem justificativas racionais para se manter; por isso essas concepções irracionalistas se difundem. Daí, a visão pós-moderna, que vem contestar a racionalidade e a própria ciência, relativizando tudo e equiparando as formas de conhecimento como se fossem equivalentes. Entendo que é esse fenômeno que foi traduzido pela Profa. Maria Célia com a expressão "recuo da teoria". É um contexto em que as demandas de mercado tendem a prevalecer e invadir todos os espaços numa orientação pragmática, guiada pela utilidade imediata. Isso também afasta a orientação teórica, dada a ausência de perspectivas que exigiriam justificativas racionais de natureza teórica. É esse o quadro que estamos vivendo traduzido na expressão "Pós-Modernidade". Daí ter eu observado no livro História das ideias pedagógicas no Brasil que as vertentes que configuram a concepção dominante atualmente não têm identidade própria. Na verdade, sua identidade é retirada das expressões anteriores às quais se antepõem os prefixos neo ou pós. É esse o quadro que se delineia na visão produtivista. O produtivismo implica essa perspectiva pragmática ligada às demandas do mercado. São os critérios de mercado que são transpostos para o campo da produção científica, consoante o conceito de produtividade analisado por Marx: produtivo é o que gera mais valia, o que acrescenta valor ao capital. Tudo acaba sendo subordinado à lógica do capital. É nesse contexto que o desenvolvimento da ciência também é marcado pelas demandas do mercado. A solução deste problema passa pela mudança da estrutura social, passa pela socialização dos meios de produção que é exigida pela socialização da produção, socialização do trabalho que o capitalismo já realizou. Lembremos que o trabalho na Idade Média era baseado no artesanato, que era um trabalho individual. $\mathrm{O}$ artesão produzia inteiramente sua obra. Cada família da gleba cultivava uma faixa de terra para atender a suas necessidades e às necessidades do senhor da terra. Mas com o capitalismo os trabalhadores foram expropriados dos meios de produção e convertidos apenas em pura força de trabalho, tendo que operar com os meios de produção concentrados nas mãos dos capitalistas. Nesse novo contexto o trabalho foi sendo socializado a tal ponto que na produção moderna praticamente a totalidade do que é produzido é resultado de exércitos de trabalhadores. O que sai dos processos de produção não é obra de um trabalhador isolado, tanto que ele não se identifica com o produto. Diferentemente do artesão que se identifica com o seu produto, o trabalhador que trabalha nas fábricas, que comportam dezenas, centenas e milhares de operários, não se identifica com os produtos do trabalho porque esses produtos são resultado do trabalho coletivo, realizado por um exército de trabalhadores, cabendo a cada um apenas uma parte do produto final, que não traz em si a marca de nenhum deles individualmente, mas tem a marca da ação de todos eles conjuntamente. Portanto, o trabalho foi socializado, mas a propriedade dos produtos do trabalho e dos meios de produção continua privada. E a bandeira do socialismo não é outra senão essa: a socialização dos meios de produção, a socia- lização da propriedade. Para deixar isso mais claro, consideremos o modo de produção anterior, o modo de produção feudal. Nesse caso, tratava-se de relações de produção baseadas na propriedade privada da terra e no trabalho dos servos, no domínio da corporação pelos mestres e no trabaIho dos artesãos, que impulsionaram as forças produtivas feudais cujo desenvolvimento conduziu a produzir mais do que o necessário para a subsistência, gerando excedentes que entraram na troca intensificando-a de tal modo que ela se tornou predominante sobre o consumo. Inverteu-se, assim, a relação entre o que era preciso para consumir e poder trocar o que sobrasse. Agora era preciso trocar para poder consumir, o que deu origem a uma nova forma de sociedade: a sociedade de mercado, sociedade burguesa, capitalista. A partir daí aquelas relações começaram a travar as forças produtivas: se os servos ficassem presos à gleba não iam poder produzir para o comércio; se os artesãos ficassem presos às corporações não podiam produzir para as fábricas e para os mercados. Então a revolução burguesa resolveu essa questão: arrancou os servos da gleba, arrancou os artesãos das corporações e os transformou em trabalhadores livres. Sob essas novas relações, as forças produtivas se desenvolveram rapidamente gerando todo esse enorme complexo de capacidade produtiva que temos hoje. Mas, a partir de agora, essas relações começam a travar as forças produtivas. Agora as forças produtivas não podem mais se desenvolver. Eis por que a sobrevida dessa forma social se baseia na destruição, pois a reconstrução do que foi destruído pode ser feita sobre a base das relações de produção vigentes que, entretanto, já não mais permitem o avanço das forças produtivas conforme a observação de Marx no prefácio à Contribuição para a crítica da economia política: "Em certo estádio de desenvolvimento, as forças produtivas materiais da sociedade entram em contradição com as relações de produção existentes ou, o que é a sua expressão jurídica, com as relações de propriedade no seio das quais se tinham movido até então. De formas de desenvolvimento das forças produtivas, estas relações transformam-se no seu entrave. Surge então uma época de revolução social". É essa a situação que estamos vivendo hoje. Um exemplo que eu tenho dado é o da obsolescência, que reduz o tempo de duração dos objetos produzidos fazendo com que seja necessário investir na reposição daquilo que deixou de funcionar. Um exemplo: embora haja tecnologia para produzir lâmpadas que nunca se queimam, os cartéis das lâmpadas não permitem que isso aconteça. Então, ficamos utilizando quantidade grande de mão-de-obra, portanto, de força de trabalho, uma quantidade grande de meios de produção para repor as lâmpadas, produzir lâmpadas para repor aquelas que se queimam. Se os meios de produção estivessem socializados, as lâmpadas não precisariam ser substituídas. Então somente seriam produzidas mais lâmpadas para atender ao aumento da necessidade de lâmpadas porque a população aumentou ou porque há mais áreas incorporadas à eletrificação. $E$ todas aquelas forças produtivas presas na produção das lâmpadas que se queimam, seriam liberadas para produzir outras coisas. Esse exemplo ilustra bem o que Marx quis dizer: 
a partir de certo momento, as relações de produção que deram impulso ao desenvolvimento das forças produtivas se convertem em freios que impedem o seu desenvolvimento. A concentração da propriedade em mãos privadas que, quando saiu dos senhores feudais e passou para a burguesia, impulsionou o desenvolvimento das forças produtivas, a partir de agora passa a travar as forças produtivas. Só com a socialização desses meios de produção as forças produtivas vão se libertar para se desenvolver. Então, também no âmbito da produção científica resolveremos os problemas do represamento das pesquisas que têm de estar atreladas às necessidades do mercado, atendendo às demandas do capital financeiro. Daí a necessidade de resistirmos a essa tendência, lutando contra a situação dominante.

Neide: Professor Saviani, pensando que toda essa exposição está direcionada a alunos da pós-graduação em Psicologia (da UEM e de outras universidades), que contempla várias teorias psicológicas, o que considera importante/ relevante para os alunos que se preparam para a docência?

Prof. Saviani: O que é importante é aquilo que é mais ou menos o óbvio: eles têm de ter o domínio da forma social em que vivem identificando o lugar da especialidade à qual eles se dedicam, que é a psicologia; e, além disso, têm de ter o domínio, caso optem pela docência, de como podem formar os outros profissionais, as outras pessoas neste campo. E aí é importante manter sempre presente a diferença entre a perspectiva do pesquisador e a perspectiva do professor. Isso vale também em relação ao ensino básico e ao ensino superior. Eles têm, ainda, de ter o domínio das teorias psicológicas e se posicionar diante delas porque não são equivalentes. E, do ponto de vista da perspectiva histórico-critica, eles deveriam se posicionar por uma teoria psicológica que dê conta da compreensão do desenvolvimento dos indivíduos humanos no interior do desenvolvimento histórico da humanidade, o que se caracteriza como um processo dialético. Por isso é que a perspectiva da pedagogia histórico-crítica converge, no campo psicológico, com a teoria da psicologia histórico-cultural; elas têm fundamentos filosóficos comuns que dão conta de problemas que as outras teorias não conseguem alcançar. Não quer dizer que as outras teorias sejam inválidas, mas elas têm um âmbito de abrangência mais restrito. Um exemplo da física talvez ilustre isso. Quando se diz que a física newtoniana foi superada pela física relativista, isso não significa que a física newtoniana perdeu sua validade. De fato ela continua válida, continua sendo referência para os fenômenos que ocorrem no espaço terrestre, mesmo quando se descobre que a terra não é uma plataforma, mas é redonda, que a terra não é o centro em torno do qual giram os outros astros, inclusive o sol, mas, ao contrário, é ela que gira em torno do sol. Os fenômenos que ocorrem na superfície terrestre não são afetados por esses fatores porque o movimento da terra é indiferente ao que ocorre na sua superfície, pois ele afeta todos os fenômenos que ocorrem na superfície da terra. Por isso, quando se quer medir o tempo que um veículo leva para se deslocar de um ponto a outro da superfície terrestre basta considerar a velocidade do veiculo e a distância. É como em matemática: quando se trabalha com frações os diferentes denominadores podem ser reduzidos a um mesmo denominador. Nesse caso ele pode ser desconsiderado visto que, por ser o mesmo, afeta os numeradores na mesma proporção. De forma semelhante, a física newtoniana é válida para os fenômenos da superfície terrestre, podendo-se desconsiderar a interveniência do movimento da terra. No entanto, quando se quer lançar um veículo para outro corpo celeste, quando se quer, por exemplo, enviar uma nave para a lua, para marte, aí a física newtoniana não dá conta porque será preciso levar em conta também o movimento da terra assim como o movimento do astro em cuja direção se faz o lançamento. Nesse caso será preciso recorrer à teoria física da relatividade que vai dar suporte para esse tipo de ação. A dialética cumpre, de alguma forma, um papel semelhante: a dialética expressa a lei do movimento da realidade. $E$ a lógica dialética é a apreensão pelos homens desse movimento. Enquanto os homens não tinham conhecimento disso eles agiam como se não existisse esse movimento e, na esfera das relações imediatas, isso não chegava a ser problema. Isso pode ser ilustrado, também, no desenvolvimento da ciência com a polêmica entre o indutivismo e o dedutivismo. Os dedutivistas invalidaram o procedimento indutivo porque pela via indutiva nunca se tem certeza do resultado obtido, pois, ao partir de casos particulares para se chegar a uma conclusão geral há sempre a possibilidade de que algum caso particular venha negar aquele resultado. Mas ai eu fiquei me perguntando: se é assim, se o raciocínio indutivo é tão precário, como é que Bacon, Galileu, Newton, deram tantas contribuições para o avanço da ciência baseados nos procedimentos indutivos? Mas acontece que eles operavam segundo o pressuposto de que a natureza se comporta de forma regular. Então, na verdade, o raciocínio deles estava apoiado no modo dedutivo do qual eles não tinham consciência porque eles não tinham visão dialética. Depois que Hegel sistematizou a lógica dialética eu volto lá e constato: o conhecimento avança não pela via indutiva, nem pela via dedutiva, mas pela via indutivo-dedutiva; os dois contrários se articulam. Então havia uma argumentação dedutiva que respaldava o raciocínio indutivo. Admitindo que a natureza se comporta de forma regular, observavam determinado fenômeno, como por exemplo, a dilatação dos metais, o comportamento dos metais diante do calor. Com isso, eles estavam constatando que se a natureza se comporta de modo regular então os metais, que são fenômenos da natureza, vão se comportar sempre de forma regular diante da ação de outro fator. Assim, diante do calor, por exemplo, os metais vão se comportar sempre da mesma maneira. Mas qual é essa regularidade? O metal se contrai, se dilata ou permanece indiferente? A resposta só será possível observando; por isso se partia da observação. Quando se constata que ele se dilata, então é possível generalizar. E basta uma observação; não é necessário sequer duas; basta uma. Se se dilata, pelo pressuposto de que a natureza se comporta de forma regular, então os metais vão sempre se dilatar. Poderiam dizer: "ah, mas porque então fazer várias observações?". Por cautela científica. Porque ao se observar que houve dilatação, é 
preciso se certificar de que se trata, mesmo, de metal e, além disso, de que a causa da dilatação foi, efetivamente, o calor. Assim, a partir da observação de alguns metais, constatado o fenômeno da dilatação se formula a hipótese da dilatação dos metais pela ação do calor e, com base nessa hipótese se pode, então, fazer uma observação controlada isolando-se determinado metal e controlando as variáveis intervenientes de modo a se colocar o metal sob a ação exclusiva do calor. Constatando-se que, nessa observação controlada, ocorre a dilatação, pode-se enunciar a lei da dilatação dos metais de forma universal: "Todo metal se dilata sob a ação do calor". Aí vêm os neopositivistas e dizem: "Mas como é que se pode garantir isso?" Do ponto de vista lógico-formal, como já constatara Aristóteles, a dedução tem a vantagem de que traz a garantia da verdade, mas tem a desvantagem de que não faz avançar o conhecimento porque o raciocínio dedutivo apenas explicita na conclusão aquilo que já está contido na premissa. Em contrapartida, o raciocínio indutivo tem a vantagem de que faz avançar o conhecimento, mas não traz a garantia da verdade, pois uma conclusão baseada em casos particulares traz sempre o risco de que algum caso não observado venha a se comportar diferentemente invalidando, pois, a conclusão geral. No entanto, ultrapassando a lógica formal e incorporando-a numa lógica superior, de caráter dialético, constato que a lei da dilatação dos metais está apoiada no pressuposto da regularidade da natureza que opera como um axioma, ou seja, como algo que não está em questão. A partir desse axioma podemos construir o seguinte raciocínio dedutivo: todos os fenômenos da natureza se comportam de forma regular (premissa maior); ora, os metais são fenômenos da natureza (premissa menor); logo, os metais se comportam de forma regular (conclusão). Então, qual será o comportamento dos metais sob a ação ao calor? Em tese, há três possibilidades: eles podem se contrair, permanecer indiferentes ou se dilatar. Para saber qual é o correto eu preciso observar. Uma vez feita a observação, ainda que de apenas um metal, e constatada a dilatação eu posso, com segurança, concluir que todos os metais se dilatam sob a ação do calor. Enfim, espero ter evidenciado que o processo de conhecimento não é nem indutivo, nem dedutivo, mas se dá por uma via que articula esses dois elementos contrários. É, portanto, indutivo-dedutivo, tal como o explica a lógica dialética para a qual os opostos se incluem, diferentemente da lógica formal que supõe a exclusão dos opostos.

Neide: Agradecemos ao senhor pela entrevista. Fique à vontade se o senhor quiser fazer alguma consideração final aos alunos e à professora.
Prof. Saviani: Queria só mandar um abraço para a Sonia e também para as outras colegas que trabalham com ela nesse programa de pós-graduação. E dizer que eu comentei alguns aspectos das questões que você levantou, dentro de um limite de tempo que extrapolei. Íamos ficar 15 minutos e ficamos uma hora. Mas são assuntos inesgotáveis, que sempre precisam ser retomados e aprofundados. Então eu desejo que o Programa vá em frente, e que a disciplina que ela está ministrando agora seja bastante frutífera para os alunos.

Agradecemos ao Professor Dermeval Saviani pela gentileza em compartilhar conosco suas experiências, análises e proposições. Trata-se de uma boa oportunidade para tratarmos da formação e da atuação de professores, em tempos tão acelerados quanto difíceis, que podem ser traduzidos por vários nomes ou termos, entre eles, por tempos de produtivismo acadêmico.

\section{Referências}

Marx, K. Crítica ao Programa de Gotha. Em: K. Marx, \& F. Engels. Obras Escolhidas. v. 2. São Paulo: Alfa-Ômega, [19--] d. p. 203234.

Moraes, M. C. M. (2001). Recuo da teoria: dilemas na pesquisa em educação. In: Reunião Anual da ANPEd, 24., Caxambu. Anais... Caxambu: ANPEd, 2001. Recuperado: 20 mai. 2003. Disponível: <http://www.anped.org.br/24/T1722216449491.DOC>.

Saviani, D. (1983). Escola e Democracia. São Paulo: Cortez/Autores Associados, $1^{\text {a }}$ edição.

Saviani, D. (1985). Ensino Público e Algumas Falas sobre Universidade. São Paulo: Cortez; Autores Associados.

Saviani, D. (1987). Política e Educação no Brasil - O Papel do Congresso Nacional na Legislação do Ensino. São Paulo, Cortez.

Saviani, D. (1998). Da Nova LDB ao Novo Plano Nacional de Educação - Por Uma Outra Política Educacional. Campinas, Autores Associados.

Saviani, D. (1999). A Nova Lei da Educação -Trajetória, Limites e Perspectivas. Campinas: Autores Associados. 
Sobre as autoras

Neide da Silveira Duarte de Matos (neide.matos@unioeste.br)

Universidade Estadual do Oeste do Paraná

Pedagoga, Mestre em Educação (UNIOESTE - PR) e doutoranda em Psicologia (UEM- PR).

Sonia Mari Shima Barroco (soniashima@uol.com.br)

Psicóloga, mestre em Educação (UEM-PR), doutora em Educação Escolar (UNESP/Araraquara - SP), pós-doutora em Psicologia Escolar e do Desenvolvimento Humano (USP-SP). 